\title{
Die Kunst des Wiederverwertens
}

\section{Erhard Taverna}

Auch in der neuen Lagerhalle in Flamatt türmen sich die Transportkisten bis unter das Dach. 32 Spitäler und 230 Pflegeheime liefern Mobiliar, Matratzen, Sanitärkeramik, Krücken, Rollstühle, Rollatoren, Beatmungsgeräte, Dialyseapparate, Kleider, Verbrauchsmaterial und Schutzmasken aus dem Pflichtlager. $\mathrm{Zu}$ den Medizingütern kommen jede Menge Schulmaterial dazu und in diesem Jahr auch stapelweise gebrauchte Computer von der SBB.

Die Warenströme aus dem Gesundheitswesen nehmen zu. Das spürt die Malteser Stiftung «Hilfe und Beistand» (www.aidass.ch) genauso, wie die kommerziellen Handelsfirmen, etwa itris Trademed AG, eine Handelsplattform, die Kunden in der ganzen Welt gebrauchte Geräten anbietet, oder MedTechTrade AG, die gut gewartete Apparate für Ultraschall und Monitoring oder Mikroskope und Pumpen mit Garantie nach Polen, Peru und Chile verkauft. Und auch ein Hilfswerk wie HIOB-International hat keine Pro-

Viele Hilfsbegehren werden durch die 125 Malteserbotschafter vor Ort weitergeleitet.

bleme, ein Netzwerk von Brockenstuben im Inland zu beliefern und dazu Spitäler in Afrika und Osteuropa mit humanitären Hilfsgütern zu versorgen.

Die Gründe für diesen verstärkten Umsatz sind vielschichtig. Für einen gesteigerten Innovations-

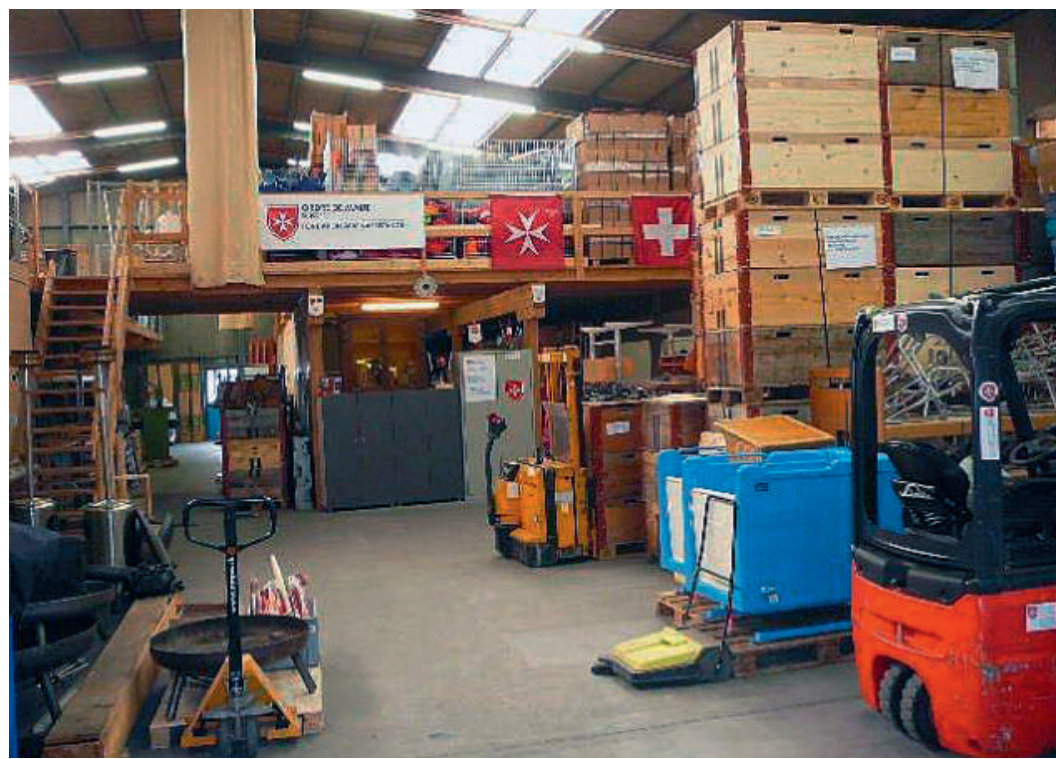

In der neuen Lagerhalle der Malteser Stiftung «Hilfe und Beistand» in Flamatt türmen sich die Transportkisten.

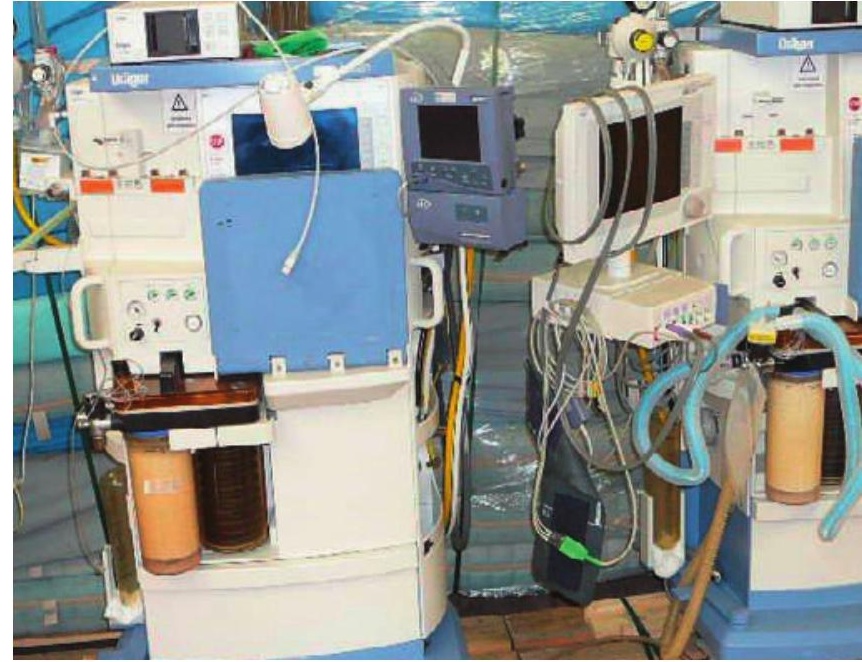

Die in der Schweiz ausrangierten Apparate werden anderswo noch gute Dienste leisten.

bedarf von Schweizer Spitälern sorgen technische Fortschritte, demographische Veränderungen, Deregulierung, verschärfter Wettbewerb und steigende Ansprüche. Die Lebenszyklen von Produkten und Dienstleistungen nehmen ab, das Segment der Privatpatienten nimmt zu und damit die Spezialisierung kleinerer und mittlerer Kliniken auf Nischenangebote. Spitalschliessungen werden durch den Ausbau der Zentren kompensiert. Da alle Prognosen mit einem weiteren Zuwachs des Gesundheitsmarktes rechnen, wird weiter investiert und erneuert. Das Schöne bei Guido Stöckli, inzwischen in der Malteser Hierarchie zum Commandeur au mérite avec épée aufgestiegen, ist die übersichtliche Firmastruktur. Ausser dem Stiftungsrat gibt es nur ihn und das langjährige kleine Kernteam ehrenamtlicher Helfer. Man könnte sie ohne Ironie die glorreichen Sieben nennen. Denn wer schafft es schon, aus einem investierten Franken das Hundertfache herauszuholen? Da gibt es natürlich noch die freiwilligen Heinzelmänner und Heinzelfrauen, die internationale Frauenorganisation Inner Wheel, das Management vom Burger King, Firmlinge, Schulklassen und die kirchliche Jugendorganisation beider Konfessionen Angel Force mit den orangen Strickmützen. Sie demontieren und reinigen, flicken und verpacken. Der Meister legt am liebsten selber Hand an, wenn er nicht im Einmannbüro am Laptop sitzt und mit Malteser International, 


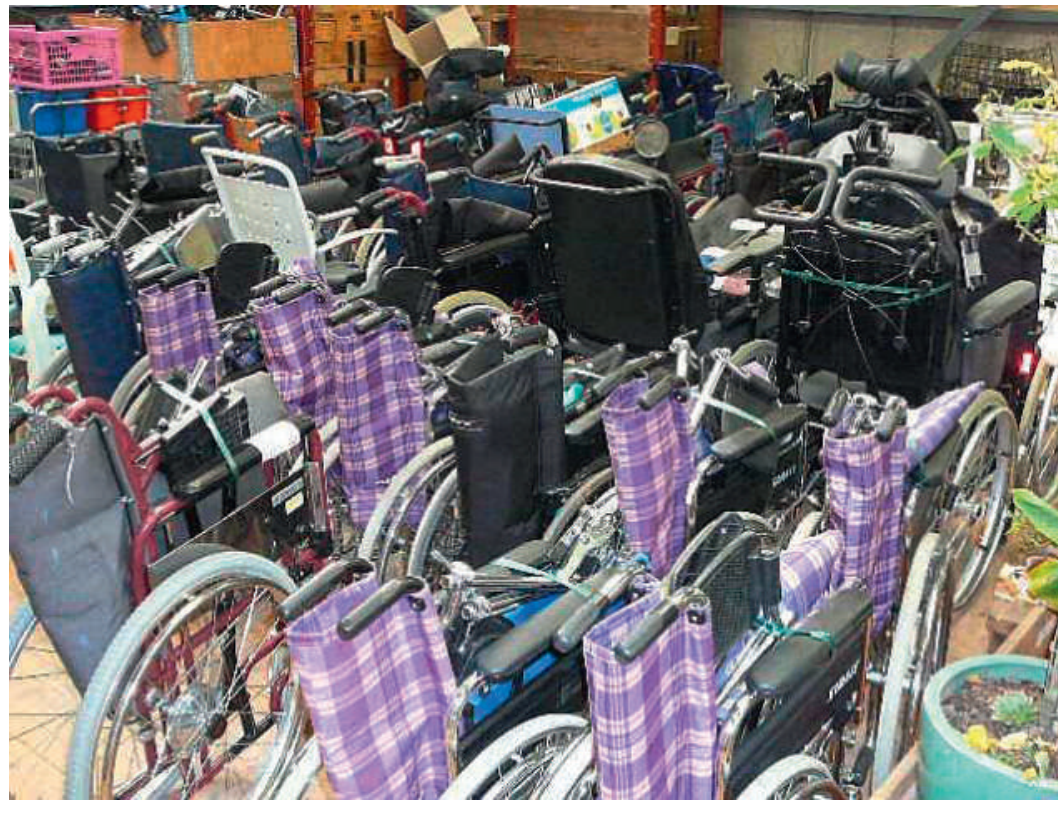

Viele Freiwillige helfen beim Verpacken der Materialien.

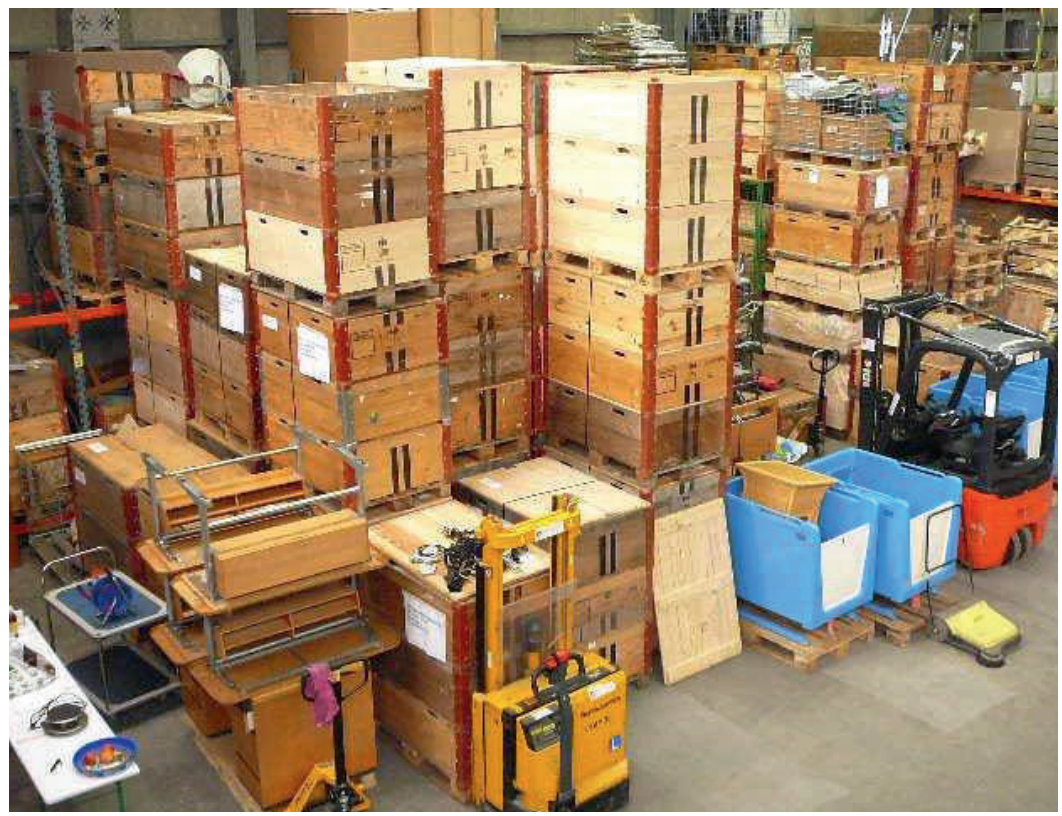

Die Warenströme aus dem Gesundheitswesen nehmen zu.
DEZA oder dem Roten Kreuz verhandelt. Etwa die Hälfte aller Hilfsbegehren wird durch die 125 Malteserbotschafter weitergeleitet. Sie sind vor Ort, kennen die Bedürfnisse, überwachen und kontrollieren nach Bedarf. Der Rest verteilt sich auf ausländische Botschaften in der Schweiz, zu denen persönliche Kontakte bestehen, oder die Anträge werden über private Vereine wie das Schweizerisch-Baltische Komitee oder Freunde der Republik Moldova gestellt. Wer in 20 Jahren 772 Sattelschlepper bewegen kann, ist eine begehrte Anlaufstelle. Schwerpunktland ist seit einiger Zeit die Slowakei, wo dank Lieferungen Spitalschliessungen vermieden und damit Arbeitsplätze gesichert wurden. Die grosse Weltpolitik wird auch in Flamatt vorstellig, wenn der Erzbischof von Aleppo mit Kleiderwünschen auf Besuch kommt, Schulmaterial in den Libanon geht, tonnenweise Kleider für syrische Flüchtlinge nach Bulgarien oder Dräger-Reanimationsgeräte nach Bethlehem geliefert werden. Auch das italienische Spital in Amman hat Bedürfnisse und Somalia hat gleich alle Liegestellen der Zivilschutzanlage von Rüeggisberg übernommen. Ein erfahrener Militär wie Guido Stöckli kann gut damit leben, dass eine amerikanische Privatfirma das Material im Inland bewaffnet transportiert. Es gibt auch Einzelinitiativen, zum Beispiel von Ärztinnen und Ärzten, die mit Malteserhilfe eine Dialysestation von Biel nach Kathmandu oder zahnärztliches Material der Uni Basel nach Kambodscha bringen. Die Computer der SBB werden mit vielen Schreibpulten Schulen in Afrika zugutekommen. Wer Millionenwerte in die Welt spediert, muss sich im Dschungel der Korruption und Druckversuche auskennen. Er muss auch ein guter Netzwerker sein, der mit Diplomaten, Bürokraten, Technikern und Medizinern verhandeln kann. Dem Mann mit der Filzjacke, dem Karohemd und den Handwerkerhosen ist der Ritter und Commandeur au mérite avec épée nicht anzusehen. Doch er weiss genau, was er will, und viele danken es ihm. 